\title{
Detection of Tornado Frequency Trend Over Ontario, Canada
}

\author{
Zuohao $\mathrm{Cao}^{*}, 1$ and Huaqing $\mathrm{Cai}^{2}$ \\ ${ }^{I}$ Cloud Physics and Severe Weather Research Section, Science and Technology Branch, Environment Canada, Toronto, \\ Ontario, Canada \\ ${ }^{2}$ National Center for Atmospheric Research, Boulder, Colorado, USA
}

\begin{abstract}
An upward trend in Ontario tornado frequency (about 1.6 tornadoes/decade with the statistically significant level at least at $95 \%$ ) is identified using three independent approaches. The first method is the conventional linear regression method that had no disturbance to the original tornado time series. The second approach is to employ the Mann-Kendall test with consideration of removing a lag one autoregressive process. The trend is further firmed up using the Monte Carlo simulation. The robustness of the detected tornado frequency trend presented in this work offers an example for tornado frequency trend analysis over other regions of the world. It is shown in this study that the Ontario tornado frequency is linked to ENSO (El Niño/Southern Oscillation) signals with a statistically significant level at $99 \%$.
\end{abstract}

Keywords: Tornado, tornado frequency trend detection, Mann-Kendall test, Monte Carlo simulation, regional climate change.

\section{INTRODUCTION}

Tornadoes are one of the most severe weather phenomena, which have high impacts on our society in terms of loss of life and damage of property. For example, each year about 80 tornadoes have been reported in Canada that lead to about 2 deaths, 20 injuries, and tens of millions of dollars in property damage (Environment Canada website: http://www.mb.ec.gc.ca/air/summersevere/ae00s02.en.html). Since tornadoes are localized short-lived phenomena, they are difficult to detect and predict. Currently, the detection and prediction of tornado almost solely rely on observations and related analyses. It is well known that the US and Canadian tornado databases are subject to various biases (e.g., [1-3]) such as population biases due to regions with greater population densities reporting more events [1], and F-scale reporting biases of weaker tornadoes [4]. Hence, caution must be exercised when one deals with the tornado dataset. In this study, both population biases and F-scale reporting biases have been taken into considerations (see next section for details). Since tornadoes are not well resolved by most (if not all) observational networks due to lack of sufficient spatial and temporal resolutions, an alternative approach is to analyze large scale environments that are favorable for tornadogenesis from a climatological perspective. Hence, it is important to perform an analysis on long-term change in tornado frequency and its association with large scale environments. The objective of this study is therefore to examine if there is any tornado frequency trend over Ontario, Canada.

\section{DATA}

Ontario is geographically located between Hudson Bay and the Great Lakes (Fig. 1). To the north of $46^{\circ} \mathrm{N}$, Ontario's

*Address correspondence to this author at the Science and Technology Branch, Environment Canada, 4905 Dufferin Street, Toronto, Ontario, M3H 5T4, Canada; Tel: 416-739-4551; Fax: 416-739-4721;

E-mail: zuohao.cao@ec.gc.ca west-east area extent is from $96^{\circ} \mathrm{W}$ to $79^{\circ} \mathrm{W}$, and to the south of $46^{\circ} \mathrm{N}$, its eastern boundary is extended to approximately $74^{\circ} \mathrm{W}$. The geographic distribution of Ontario tornadoes can be found in Fig. (1) of [9]. Fig. (2a) shows Ontario tornado event number per year over the time period of 1950-2007. The quality-controlled data for tornado events and days over Ontario are obtained from [1] and the Ontario Storm Prediction Center (OSPC) of Environment Canada [5-7], respectively. The data set contains numbers of tornado events (i.e., one event is for one tornado) and days over 58 years (1950-2007), in which [1]'s dataset covers the period before 1979 and OSPC dataset covers the period of 19792007. [1] developed a probabilistic approach to rate tornadoes using the categories of confirmed, probable and possible. OSPC mainly adapted these categories with an emphasis on confirmed and probable categories. For Ontario tornado data, the population bias was taken into account by [1]'s work. Based on [8], the population bias does not impact the reports significantly. Since 1979 tornado sightings were routinely archived by Environment Canada and in 1985 the first Doppler radar was used over Ontario. The radar observations provide additional information for tornado analysis, for example, verification of reported tornado events using radar images. Therefore, the Ontario frequency data may be truly representative of the actual numbers of tornado events $[9,10]$. In this work, we are interested in all F-scale tornadoes because few F1 or stronger tornadoes occur each year in Ontario. To understand the effect of reporting bias of weak tornadoes such as F0 on the tornado frequency trend analysis, we have also employed the tornado time series with scales of $\mathrm{F} 1$ and greater.

\section{TORNADO FREQUENCY TREND}

The intention of this study is to detect a deterministic trend (systematic changes over mean), not a stochastic trend introduced by a red noise process that can be represented by an $A R(1)$ (a lag one autoregressive) process. Since the existence of positive serial correlation of AR(1) in a time series increases the probability of detection of a significant 


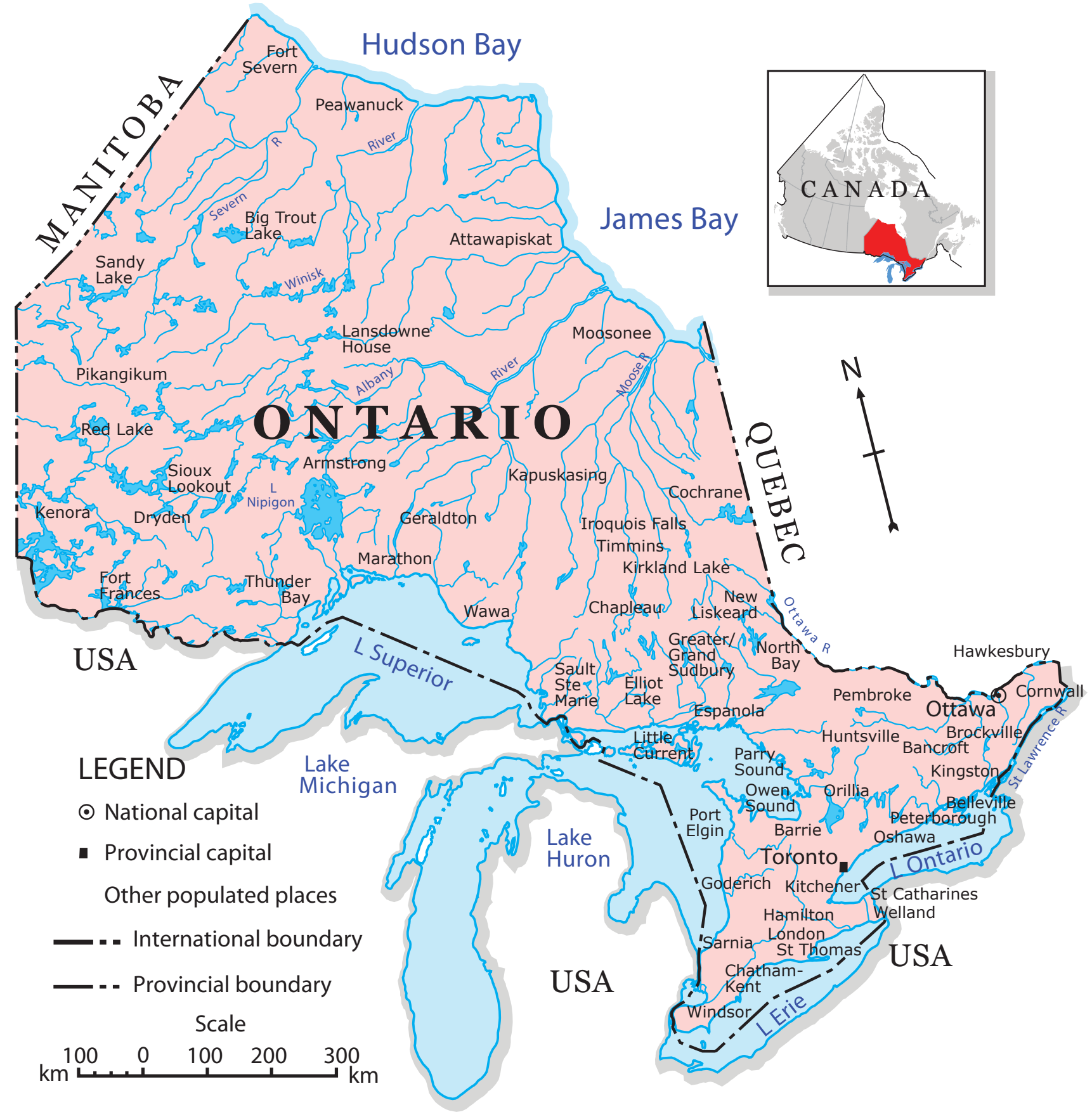

Fig. (1). The map of Ontario, Canada.

trend by the MK test, [11] suggested to remove the AR(1) from the time series through a pre-whitening procedure. To decide if the AR(1) process needs to be removed from the original time series (Fig. 2), we calculate the autocorrelation coefficient, and then perform a statistical test to see if it is significant. It is found that the AR(1) process appeared in the tornado time series is statistically significant at $95 \%$ level. To eliminate the effect of AR(1) process on detection of the deterministic trend, as [11] suggested, we need to remove the $\mathrm{AR}(1)$ process from the time series through a pre-whitening procedure. However, this pre-whitening also removes a portion of the trend as demonstrated by [12]. To detect a trend properly, we use a trend-free pre-whitening approach [e.g., 6-7, 12] prior to applying the statistical test. The trendfree pre-whitening approach basically requires that the original time series is detrended before removing the AR(1) process, and this trend is then blended with the time series after removing the $\mathrm{AR}(1)$ process. As a result, the true trend is preserved and it is no longer influenced by the effects of autocorrelation. 

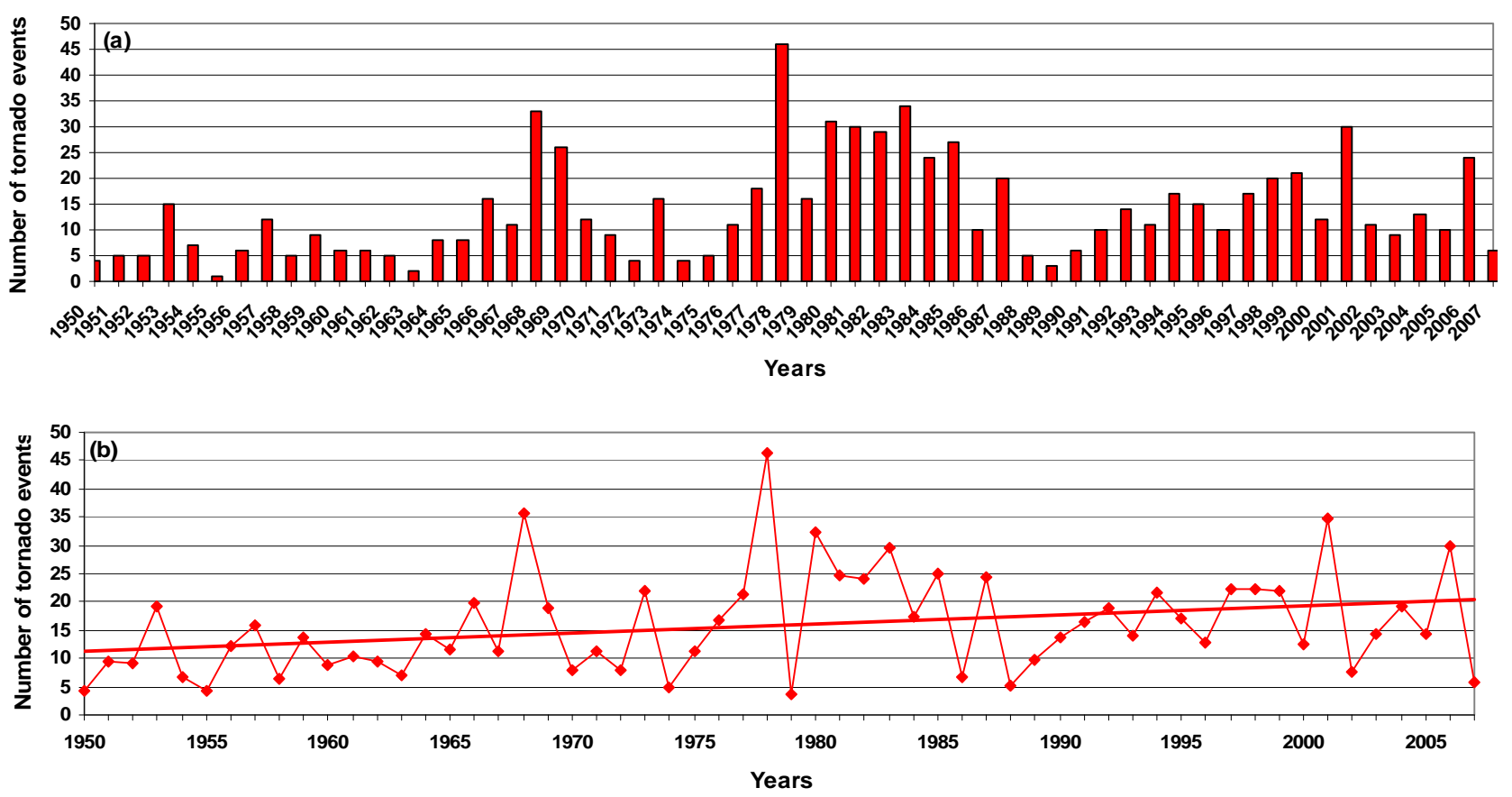

Fig. (2). (a) A histogram of Ontario tornado event number over the time period of 1950-2007, and (b) the time series of tornado event number (1950-2007) over Ontario and its trend after removing the AR(1) process.

After applying the trend-free pre-whitening procedure to the Ontario tornado frequency time series, we have employed the widely-used nonparametric Mann-Kendall (MK) $[13,14]$ statistical test. Under the null hypothesis $H_{o}$ that a sample of data $\left\{X_{i}, i=1,2, \ldots, \mathrm{n}\right\}$ is independent and identically distributed, the MK test statistic $\mathrm{S}$ is defined as:

$S=\sum_{i=1}^{n-1} \sum_{j=i+1}^{n} \operatorname{sgn}\left(X_{j}-X_{i}\right)$

where

$\operatorname{sgn}(\theta)=\left\{\begin{array}{cll}1 & \text { if } & \theta>0 \\ 0 & \text { if } & \theta=0 \\ -1 & \text { if } & \theta<0\end{array}\right.$.

[13-14] showed that when $\mathrm{n} \geq 8$, the statistic $\mathrm{S}$ is approximately normally distributed with the mean and the variance as follows:

$E(S)=0$,

$\sigma_{S}^{2}=\frac{1}{18}\left[n(n-1)(2 n+5)-\sum_{i=1}^{m} t_{i}\left(t_{i}-1\right)\left(2 t_{i}+5\right)\right]$,

where $m$ is the number of tied (i.e., equal values) groups, and $t_{i}$ is the number of data points in the $i$ th tied group. Under the null hypothesis, the standardized MK statistic $\mathrm{Z}$ follows the standard normal distribution with mean of zero and variance of one:

$$
Z=\left\{\begin{array}{cll}
(S-1) / \sigma_{S} & \text { if } & S>0 \\
0 & \text { if } & S=0 \\
(S+1) / \sigma_{S} & \text { if } & S<0
\end{array} .\right.
$$

If $|Z|>Z_{1-\alpha / 2}$, a trend is statistically significant at a level of $1-\alpha / 2$.

As shown in Table 1, the computed $\mathrm{Z}$ statistic is greater than $Z_{1-\alpha / 2}$ at different significance levels. It demonstrates that the upward trend of Ontario tornado frequency is at least significant at the level of $99 \%$. After removing the AR(1) process, we have plotted this upward trend of tornado frequency in Fig. (2b). Based on our calculation, the trend is about 1.6 tornadoes/decade with the statistically significant level at least at $99 \%$.

Table 1. Mann-Kendall Test for Trend Detection of Ontario Tornado Frequency

\begin{tabular}{|c|c|c|c|}
\hline$Z$ Statistic & 2.62 & - & - \\
\hline$Z_{1-\alpha / 2}$ & 2.58 & 1.96 & 1.65 \\
\hline$\alpha$ & 0.01 & 0.05 & 0.10 \\
\hline
\end{tabular}

We also perform an independent trend analysis using a conventional linear regression approach. The advantage of this method is that it does not disturb the original time series. 


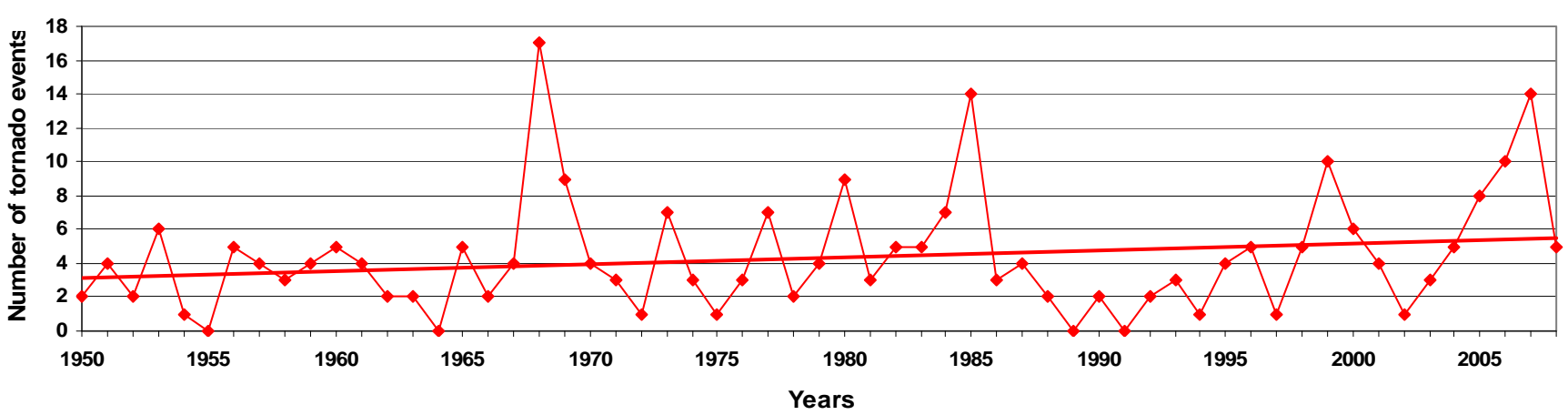

Fig. (3). The time series of tornado event number (1950-2007) over Ontario and its trend after excluding F0 tornado events.

It is identified through a $\mathrm{t}$ test that this upward trend is statistically significant at the level of $95 \%$.

To further firm up this finding, a Monte Carlo method [e.g., 15] is employed to assess the statistical significance of the detected trend. The original time series of Ontario tornado frequency is shuffled using a random number generator, which is a standard intrinsic function in Fortran 90 (http://www.nsc.liu.se/ boein/f77to90/a5.html). A linear regression slope is then computed. After repeating these processes for 1000 times, we have sorted out these slopes in an ascending order, and obtained the $950^{\text {th }}$ test statistic (the absolute value of the slope for a two-tailed test). We have found that the slope with the original time series is greater than the $950^{\text {th }}$ test statistic, indicating that the detected trend is statistically significant at $95 \%$ level.

To address the issue on the reporting bias of weak tornadoes, we have excluded all F0 tornadoes but kept all tornadoes with scales of F1 and greater in order to have a reasonable sample size [e.g., 16], and re-done the t statistical test with the new time series. As illustrated by [17], excluding F0 tornadoes would likely address most of the reporting bias of weak tornadoes. The time series of F1 or greater tornado was more stationary over time as opposed to the time series of F2 or greater [17]. With this new time series, we have found that the upward trend (Fig. 3) is still statistically significant at the level of $95 \%$. Therefore, we believe that the detected upward trend is robust.

To further explore if the tornado frequency trend is linked to external forcings such as ENSO, we examine the relationship between the multivariate ENSO Index (MEI) [18] averaged over 7 month (March to September) period [9], and the tornado frequency over Ontario. As a result, the correlation coefficient between the averaged MEI index and the time series of Ontario tornado frequency reaches 0.34 , which exceeds a statistical significant level of $99 \%$.

\section{CONCLUSIONS}

In this study, we have examined Ontario tornado frequency changes over the last almost six decades. It is found for the first time that over the last six decades the tornado frequency exhibits an increasing trend. The robustness of this upward trend is established using three independent methods: (1) the conventional linear regression with no disturbance to the original tornado time series, (2) the MK statistical test with consideration of removing the AR(1) process, and (3) the Monte Carlo simulation.
It is found in this study that the Ontario tornado frequency is associated with ENSO signals with a statistically significant level at $99 \%$. More research work needs to be carried out in the future in order to detail the physical processes responsible for the detected tornado frequency trend. Although these topics are beyond the scope of the current paper, they are definitely very interesting issues for future studies.

\section{ACKNOWLEDGEMENTS}

The authors would like to thank the Ontario Storm Prediction Center of Environment Canada for providing the tornado frequency data over Ontario of Canada.

\section{REFERENCES}

[1] Newark MJ. Canadian tornadoes, 1950 to 1979. Atmos Ocean 1984; 22: 343-53.

[2] Grazulis TP, Schaefer JT, Abbey RF. Advances in tornado climatology, hazards, and risk assessment since Tornado Symposium II, In The Tornado: Its Structure, Dynamics, Prediction and Hazards. Geophysical Monograph, Church C, Burgess D, Doswell C, Davies-Jones R, Eds. Am Geophysic Union 1993; 79: 409-26.

[3] Snider CR. A look at Michigan tornado statistics. Mon Wea Rev 1977; 105: 1341-2.

[4] Feuerstein B, Dotzek N, Grieser J. Assessing a tornado climatology from global tornado intensity distributions. J Climate 2005; 18 : 585-96.

[5] Cao Z, Cai H. Tornado frequency and its large-scale environments over Ontario, Canada. Open Atmosph Sci J 2008; 2: 256-60.

[6] Cao Z. Severe hail frequency over Ontario, Canada: recent trend and variability, Geophys Res Lett 2008; 35: L14803.

[7] Cao Z, Ma J. Summer severe rainfall frequency trend and variability over Ontario, Canada. J Appl Meteor Climatol 2009; 48: $1955-60$

[8] King P. On the absence of population bias in the tornado climatology of southwestern Ontario. Wea Forecast 1997; 12: 93946.

[9] Etkin D, Brun SE, Shabbar A, Joe P. Tornado climatology of Canada revisited: tornado activity during different phases of ENSO. Int J Climatol 2001; 21: 915-38.

[10] Sills DML, Scriver SJ, King PWS. The Tornadoes in Ontario project (TOP), 22nd AMS Conference on Severe Local Storms. Am Meteorol Soc 2004; CD-ROM Paper 7B 5.

[11] von Storch H. Misuses of statistical analysis in climate research, Analysis of Climate Variability Applications of Statistical Techniques: von Storch H, Navarra A, Eds. Springer: New York 1995.

[12] Yue S, Wang CY. Regional streamflow trend detection with consideration of both temporal and spatial correlation. Int $\mathrm{J}$ Climatol 2002; 23: 933-46.

[13] Mann HB. Nonparametric test against trend. Econometrica 1945, 13: 245-59.

[14] Kendall MG. Rank Correlation Methods. Charles Griffin: London 1975. 
[15] Chu PS, Wang JB. Recent climate change in the tropical western Pacific and Indian Ocean regions as detected by outgoing longwave radiation records. J Climate 1997; 10: 636-46.

[16] Doswell CA III. Small sample size and data quality issues illustrated using tornado occurrence data. Electronic J Severe Storms Meteor 2007; 2(5): 1-16.
[17] Verbout SM, Brooks HE, Leslie LM, Schultz DM. Evolution of the U.S. tornado database: 1954-2003. Wea Forecast 2006; 21: 86-93.

[18] Wolter K, Timlin MS. Measuring the strength of ENSO events how does 1997/98 rank? Weather 1998; 53: 315-24.

(C) Cao and Cai; Licensee Bentham Open.

This is an open access article licensed under the terms of the Creative Commons Attribution Non-Commercial License (http: //creativecommons.org/licenses/by$\mathrm{nc} / 3.0 /$ ) which permits unrestricted, non-commercial use, distribution and reproduction in any medium, provided the work is properly cited. 